\title{
Serum Vitamin Levels among Iraqi Cancer Patients Receiving Chemotherapy
}

\author{
Mohammed Salim Abdulrahman ${ }^{1 *}$, Hedef D. El-Yassin ${ }^{1}$, Nada A. S. Alwan ${ }^{2}$ \\ ${ }^{1}$ Department of Clinical Biochemistry, College of Medicine, University of Baghdad, Iraq; ${ }^{2}$ National Cancer Research Center, \\ University of Baghdad, Iraq
}

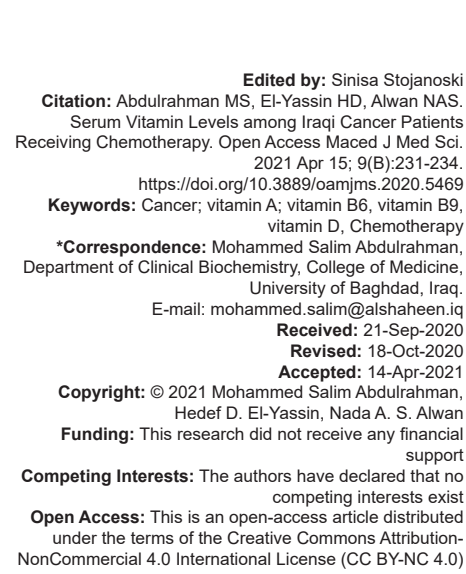

Introduction

Cancers are a broad entity of complex diseases with an irregular pattern of cell growth that can invade or metastasize other areas of the organism. It is the world's leading death cause; 9.6 million deaths were reported in 2018. The most common causes of cancer-related deaths are cancers of the lungs, breasts, stomach, and colon [1].

Vitamins deficiency could lead to human body disequilibrium involving malnutrition processes and endocrine dysfunction, that could be mediated by the tumor pathology itself or by the associated therapy [2], [3].

Early detection and prompt correction of vitamins disorders can improve patients' short-term outcome and quality of life [4], [5]. Vitamin disorders in cancer patients and its relationship with the clinical outcomes have been the focus of investigation in many studies.

In this study we aimed to assess the serum vitamins level changes in patients with cancer pre and post chemotherapy.

\section{Materials and Methods}

A cohort study was carried out on newly diagnosed patients with cancer before undergoing chemotherapy treatment in Al-Amal National Radiation Oncology Hospital/Baghdad/Iraq during the period from January 2019 to July 2019. The study protocol was approved by our institutional review board in line with the principles of the Declaration of Helsinki. Assessments of the studied samples were conducted basically before receiving chemotherapy or radiotherapy application and referred to as T0; whereas evaluation after the third cycle of chemotherapy was termed as $\mathrm{Tx}$.

\section{Patients criteria for inclusion}

The following criteria were included in the study:

(1) All newly diagnosed patients with cancer aged therapy who did not yet start the first cycle of chemotherapy regimen; and (3) those who are in a 
competent mental and physical status and willing to participate in the study team.

\section{Patient criteria for exclusion}

The following criteria were excluded from the study:

(1) Patients who are already started the chemotherapy regiment; (2) patients who are unable to answer the questionnaires (due to physical or mental impairment); and (3) deteriorated performance status participants.

\section{Quantitative parameters}

Anthropometric measurement included weight, height, and body mass index (BMI). Quantitative dietary assessment was made for vitamins: A, B1, B2, B3, B6, B12, folic acid, D, and E.

One hundred Iraqi patients with carcinoma of various types, grades, and stages have been sequentially evaluated before chemotherapy and radiotherapy, regardless of their chemical purposes (curative, neoadjuvant, adjuvant, or palliative). They were selected in the waiting room for a medical test at the cancer center in the hospital. The patients' approval was confirmed by signing written formal consents. The follow-up time depending on the chemotherapy treatment was about $2-3$ months. The chemical parameters were measured using ELISA technique.

Data of patients were analyzed using SPSS software version 25. Descriptive statistics were tabulated as mean, standard deviation, range, frequencies, and proportions. Paired Student's t-test for variables levels was utilized. Level of significance of $\leq 0.05$ was considered as significant difference of correlation.

\section{Results}

One hundred patients were enrolled in this study. The mean age was $50.15 \pm 13.08$ years, $77 \%$ were women. Most of the patients $78(78 \%)$ were from Baghdad and the rest from other different provinces of Iraq. Comorbidity was reported in $38 \%$ of the cases. Mean Body surface area (BSA) of patients in this cohort was $1.7 \pm 0.23$ and mean Body mass index (BMI) of the patients was $30.62 \pm 5.51 \mathrm{~m}^{2} / \mathrm{Kg}, 45 \%$ of the patients were obese. Details are shown in Table 1.

The majority of patients of the sample studied were breast cancer females about 55(55\%) followed by $14 \%$ colorectal; $11 \%$ lung other type of cancer are illustrated in Figure $1 \mathrm{~A}$.
Table 1: Demographic distribution of the study population $(n=100)$

\begin{tabular}{|c|c|c|}
\hline Variables & & No $(\%)$ \\
\hline \multirow[t]{3}{*}{ Gender } & Male & $23(23)$ \\
\hline & Female & $77(77)$ \\
\hline & Total & 100 \\
\hline \multirow[t]{8}{*}{ Age } & $<20$ & $1(1)$ \\
\hline & $20-30$ & $7(7)$ \\
\hline & $31-40$ & $14(14)$ \\
\hline & $41-50$ & $30(30)$ \\
\hline & $51-60$ & $25(25)$ \\
\hline & $61-70$ & $18(18)$ \\
\hline & $>70$ & $5(5)$ \\
\hline & Total & 100 \\
\hline \multirow[t]{3}{*}{$\operatorname{BSA}\left(m^{2}\right)$} & $<1.65$ & $38(38)$ \\
\hline & $>1.65$ & $62(62)$ \\
\hline & Total & 100 \\
\hline \multirow[t]{5}{*}{$\mathrm{BMI}\left(\mathrm{m}^{2} / \mathrm{kg}\right)$} & Underweight $<18.5$ & $5(5)$ \\
\hline & Normal (18.6-24.9) & $20(20)$ \\
\hline & Overweight (25-29.9) & $30(30)$ \\
\hline & Obese $>30$ & $45(45)$ \\
\hline & Total & 100 \\
\hline \multirow[t]{10}{*}{ Address } & Babil & $1(1)$ \\
\hline & Baghdad & $78(78)$ \\
\hline & Basra & $1(1)$ \\
\hline & Diyala & $2(2)$ \\
\hline & Misan & $1(1)$ \\
\hline & Mosul & $2(2)$ \\
\hline & Ramadi & $4(4)$ \\
\hline & Tikrit & $5(5)$ \\
\hline & Wasit & $6(6)$ \\
\hline & Total & 100 \\
\hline \multirow[t]{7}{*}{ Occupation } & Employee & $12(12)$ \\
\hline & Engineer & $3(3)$ \\
\hline & Housewife & $60(60)$ \\
\hline & Non- employer & $17(17)$ \\
\hline & Student & $2(2)$ \\
\hline & Teacher & $6(6)$ \\
\hline & Total & 100 \\
\hline \multirow[t]{3}{*}{ Comorbidity } & Present & $38(38)$ \\
\hline & Not & $62(62)$ \\
\hline & Total & 100 \\
\hline
\end{tabular}

The chemotherapeutic protocol are shown in figure $1 \mathrm{~B}$, the Adriamycin/Cyclophosphamide +Taxen protocol prescribed in $54 \%$, followed by $16 \%$ Carboplatin and Taxen. 14\% patients received Xelox. Five percent of patients kept on Gemcitabine, and another $5 \%$ of patients kept on Taxen. Three percent of patients given 5FU+Cisplatin. 2\% lymphoma patients given ABVD. $1 \%$ patients received FOLFIRINOX (Figure 1).

The level of vitamins showed alteration after chemotherapy administration (Table 2). Vitamin A level reduced significantly post- chemotherapy ( $P$ value $=0.0003)$, similarly, Vitamin $E, B 12$ and $B 9(P<0.0001)$. The baseline level of vitamin D and B6 of patients in our cohort were lower than normal value, after chemotherapy both were significantly increased $(P=0.0038, P<0.0001)$ respectively, yet remain below the normal value.

Table 2: Vitamins concentration pre- and post- chemotherapy

\begin{tabular}{lllll}
\hline Vitamin & $\begin{array}{l}\text { Normal } \\
\text { value }\end{array}$ & $\begin{array}{l}\text { Pre } \\
\text { chemotherapy }\end{array}$ & $\begin{array}{l}\text { Post } \\
\text { chemotherapy }\end{array}$ & P- value \\
\hline Vitamin A $(\mu \mathrm{mol} / \mathrm{L})$ & $0.7-3.5$ & $0.64 \pm 0.23$ & $0.51 \pm 0.26$ & $0.0003^{*}$ \\
Vitamin $\mathrm{E}(\mu \mathrm{mol} / \mathrm{L})$ & $12-42$ & $19.47 \pm 4.714$ & $14.70 \pm 5.354$ & $<0.0001^{*}$ \\
Vitamin D $(\mathrm{pmol} / \mathrm{L})$ & $60-108$ & $21.11 \pm 7.21$ & $26.55 \pm 15.22$ & $0.0038^{*}$ \\
Vitamin B6 $(\mathrm{nmol} / \mathrm{L})$ & $20-121$ & $4.19 \pm 1.94$ & $8.22 \pm 5.39$ & $<0.0001^{*}$ \\
Vitamin B12 $(\mathrm{pmol} / \mathrm{L})$ & $206-735$ & $366.0 \pm 95.94$ & $291.1 \pm 102.6$ & $<0.0001^{*}$ \\
Vitamin B9 $(\mathrm{nmol} / \mathrm{L})$ & $12.2-40.8$ & $16.13 \pm 4.13$ & $12.96 \pm 5.87$ & $<0.0001^{*}$ \\
\hline
\end{tabular}

\section{Discussion}

Cancer management is a long painful experience regardless of the outcomes. This suffering 


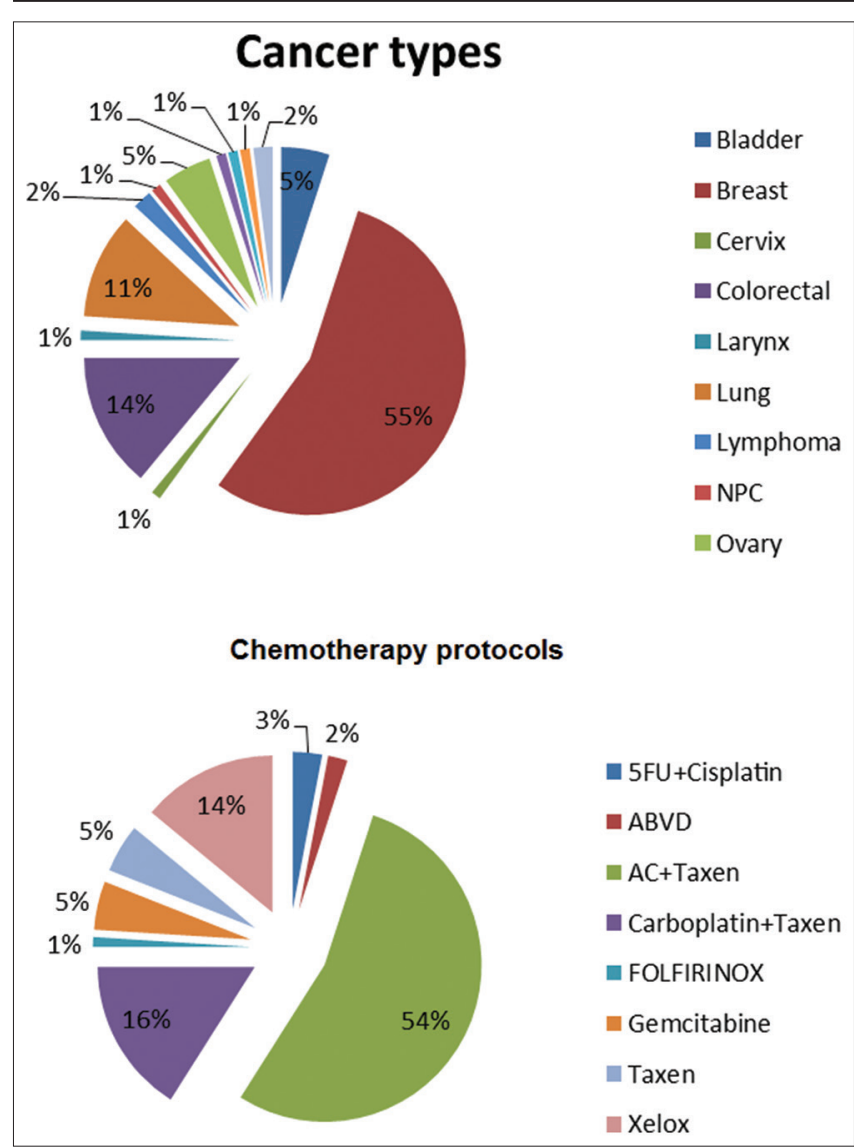

Figure 1: Pie charts of cancer types and chemotherapy protocols

in part is mediated by the underlying changes in electrolytes, vitamins, elements, and neurotransmitters. The, the objective of this study was to shed light on area and link changes together to formulate a detailed picture about the metabolic changes in cancer patients. Such data may be of value in the future management and research on cancer patients with the aim of improving therapy outcomes and the quality of life.

Vitamin A serum levels showed a significant decrease. This finding is in accordance with that of a previous study [6]. It is obvious that vitamin $A$ intake less than the recommended daily allowance (RDA) is mainly due to loss of appetite, nausea, and vomiting induced by drugs and disease status as cancer is a highly catabolic state [7].

Vitamin $E$ serum levels decreased pre- to post-chemotherapy state with high significance. Similar findings were reported in an earlier report [6] highlighting the problem of malnutrition that affects multiple vitamins during the course of chemotherapy.

Ontheotherhand, VitaminDserumlevelsshowed statistically significant increase, that was consistent with the observation recorded by an earlier study [6]. The variations in the level in other surveys could be attributed to huge variation in the doses of Vitamin $D$ administered to patients on chemotherapy programs which could reflect mismanagement in diagnosing and treating
Vitamin D deficiency. In general, high intake of Vitamin D supplements during the chemotherapy courses or cycles is recommended, especially for those patients with breast cancer. Hypervitaminosis D constitutes an additional problem through interacting with other nutritional vitamins and elements. It causes nausea, anorexia, and constipation as well as mild acidosis, anemia, or weight loss through metabolic processes [8], [9]. The symptoms of Vitamin D toxicity are mediated by hypercalcemia, hypercalciuria, and hyperphosphatemia. Moreover, it may result in renal stones, polyuria and polydipsia, and hypertension [10], [11]. Chemotherapy without Vitamin D supplements ultimately result in Vitamin D deficiency [12], [13].

Vitamin B6 serum levels also revealed highly statistical significance increase. Similar findings were noted by other researchers [6], [14]. Vitamin B6 is commonly given to cancer patients, especially during chemotherapy courses as supplement assisting as an antiemetic. It is evident from the results that the standard deviation of B6 level post-chemotherapy is much higher than that recorded pre-chemotherapy. This also indicates the great variation in the intake of Vitamin B6 among various cancer patients causing mismanagement in terms of choosing the proper dose of Vitamin B6 to be administered. However, B6 levels (pre- and post-chemotherapy) are much lower than normal level (20-121 nmol/L). Vitamin B6 intake, in general, was still much less than the RDA [6], [15], [16]. Thus, further assessment of the required doses during chemotherapy is recommended.

B12 vitamin serum levels were considerably declined post-chemotherapy. Identical results have been observed by others [17], [18] highlighting the essential role of Vitamin B12 and demonstrating that elevated rates of serum Vitamin B12 can be used in metastatic cancer patients to estimate survival time.

The rates of folate displayed a decline with strong statistical significance. Folic acid is the first be transformed into the cofactors dihydrofolate (DHF) and tetrahydrofolate (THF) inside the body. To prevent DNA synthesis in rapidly splitting cells, and thereby escape $\mathrm{DHF} / \mathrm{THF}$ formation, this critical path is interrupted by anti-metabolite therapies like methotrexate (MTX) because they act as DHFR inhibitors. MTX, as taken in large concentrations, like in the diagnosis of cancer, or in small amounts, like in rheumatoid arthritis or psoriasis, stops the body from producing folic acid. This leads to a deficiency of coenzymes and the resulting increase in toxic substances that cause many adverse side effects. As a consequence, 1-5 mg folic acid is prescribed as a treatment to avoid malnutrition as well as MTX-related side effects involving mouth ulcers and gastrointestinal discomfort [19], [20]. In the absence of elevated consumption, malignancy is a catabolic condition synonymous with lower serum folate rates [21], [22]. 


\section{Conclusion}

Cancer patients on chemotherapy regimens are suffering from major changes in the levels of vitamins that are affecting their lifestyle, treatment course, survival, and prognosis. Frequent regular monitoring for such changes is required to harvest a positive impact on cancer patients lifestyle and treatment outcome. Chemotherapeutic regimens need to be updated in terms of quality and quantity according to the peculiar status of the patient in terms of nutritional status and neurotransmitters changes.

\section{References}

1. World Health Organization. Global Health Observatory. Geneva: World Health Organization; 2018. Available from: https://www. who.int/gho/database/en. [Last accessed on 2018 Jun 21].

2. Rosner MH, Capasso G, Perazella MA. Acute kidney injury and electrolyte disorders in the critically ill patient with cancer. Curr Opin Crit Care. 2017;23(6):475-83. https://doi.org/10.1097/ mcc. 0000000000000450

PMid:28953555

3. Abranches MV, Mendes MC, Pena G, Maia YC, Ribeiro SM, Franceschini SD, et al. Antioxidant vitamins and cytokines are altered in breast cancer. Eur J Cancer Prev. 2011;20(5):403-10. https://doi.org/10.1097/cej.0b013e328347618e PMid:21566526

4. Yang $Y$, Sun N, Sun P, Zhang L. Clinical characteristics and prognosis of elderly small cell lung cancer patients complicated with hyponatremia: A retrospective analysis. Anticancer Res. 2017;37(8):4681-6. https://doi.org/10.21873/anticanres.11872 PMid:28739771

5. Al-Attar Z. The prevalence and antimicrobial sensitivity of Esbl Escherichia Coli. in clinical isolates. Al Kindy Coll Med J. 2014;10(1):49-52.

6. Mohammed DS, Daoud FA. Assessment of dietary intake in patients with breast cancer receiving chemotherapy. Int J Sci Res. 2015;4(11):1520-5.

7. Schiessel DL, Baracos VE. Barriers to cancer nutrition therapy: Excess catabolism of muscle and adipose tissues induced by tumour products and chemotherapy. Proc Nutr Soc. 2018;77(4):394-402. https://doi.org/10.1017/ s0029665118000186 PMid:29708079

8. de Azevedo FR, Caramelli B. Hypovitaminosis D and obesitycoincidence or consequence? Eur Endocrinol. 2013;9(2):128-31. PMid:29922368

9. Nashtar SB, Hashim I, Al-Attar Z. The effect of parsley in the treatment of UTI in Iraqi patients. Int J Med Res Health Sci. 2018;7(8):1-7.

10. Ghauri MI, Bareeqa SB, Riaz A, Kumar A. Redundancy is of no good; iatrogenic hypervitaminosis D: A rare case of persistent vomiting due to hypercalcemia. Clin Med Insights Case Rep. 2019;12:1179547619828688. https://doi. org/10.1177/1179547619828688

PMid:30792578

11. Al-Attar SJ, Hashim I. Prevalence of anemia types among overweight and obese patients attending the obesity research and therapy unit at AL-Kindy College of medicine. Int Med J. 2020;25(1):435-48

12. Fakih MG, Trump DL, Johnson CS, Tian L, Muindi J, Sunga AY Chemotherapy is linked to severe Vitamin $D$ deficiency in patients with colorectal cancer. Int J Colorectal Dis. 2009;24(2):219-24. https://doi.org/10.1007/s00384-008-0593-y PMid: 18830610

13. Al-Attar Z, Hashim I, Nashtar SB. The role of nucleo-CMP as an adjuvant agent in the treatment of facial palsy. Int $\mathrm{J}$ Med Res Health Sci. 2018;7(3):161-7.

14. Custodio ID, Eda CM, Gontijo CA, Pereira TS, Paiva CE, Maia YC. Impact of chemotherapy on diet and nutritional status of women with breast cancer: A prospective study. PLoS One. 2016;11(6):e0157113. https://doi.org/10.1371/journal. pone. 0157113

PMid:27310615

15. Al-Attar Z, Faulkner L, Farrell J, Whitaker P, Peckham D, Park K et al. Characterization of the TCR $\vee$ repertoire of piperacillinspecific T-cells. Clin Transl Allergy. 2014;4(S3):P39. https://doi. org/10.1186/2045-7022-4-s3-p39

16. Al-Attar Zl. Irritable bowel syndrome: The most common presentation, severity ranking and therapeutic regimens among patients attending outpatient. AL Kindy Coll Med J. 2020;16(1):10-7. https://doi.org/10.47723/kcmj.v16i1.183

17. Oh HK, Lee JY, Eo WK, Yoon SW, Han SN. Elevated serum Vitamin B12 levels as a prognostic factor for survival time in metastatic cancer patients: A retrospective study. Nutr Cancer. 2018;70(1):3744. https://doi.org/10.1080/01635581.2018.1397711 PMid:29220583

18. AL-Jawad FH, Hashim HM, Al-Attar Z, Al-Ani AH. Changing the Lipid Profile and Renal Functions by Allium sativum, Nigella sativa and Hibiscus sabdariffa in Essential Hypertensive Patients; 2018.

19. Liu L, Liu S, Wang C, Guan W, Zhang Y, Hu W, et al. Folate supplementation for methotrexate therapy in patients with rheumatoid arthritis: A systematic review. J Clin Rheumatol. 2019;25(5):197-202. https://doi.org/10.1097/ rhu. 0000000000000810 PMid:29975207

20. Al-Jawad FH, Al-Attar Z, Abbood MS. The protective effect of nitroglycerin, $\mathrm{N}$-acetyl cysteine and metoprolol in CCL4 induced animal model of acute liver injury. Open Access Maced J Med Sci. 2019;7(11):1739-43. https://doi.org/10.3889/oamjms.2019.469 PMid:31316651

21. Saleh AM, Pheasant AE, Blair JA, Allan RN, Walters J. Folate metabolism in man: The effect of malignant disease. Br J Cancer. 1982;46(3):346-53. https://doi.org/10.1038/bjc.1982.210 PMid:6982057

22. Hamdan SJ, Al-Attar Z, Hashim I. Prevalence of montelukast use as an add-on therapy among Iraqi asthmatics on treatment attending Al-Kindy Teaching Hospital and Al-Zahraa Center of asthma and allergy. Open Access Maced J Med Sci. 2019;7(14):2246-50. https://doi.org/10.3889/oamjms.2019.645 PMid:31592270 